\title{
Octopamine affects the timing of retinal responses in Limulus as well as their amplitudes
}

\section{G. S. Wasserman*, A. R. Bolbecker, J. Li and C. C. M. Lim-Kessler}

Sensory Coding Laboratory, Department of Psychological Sciences, Purdue University, Lafayette, IN, USA

*Correspondence: codelab@purdue.edu

\section{A commentary on}

Octopaminergic modulation of temporal frequency coding in an identified optic flow-processing interneuron

by Longden, K. D., and Krapp, H. G. (2010).

Front. Syst. Neurosci. 4:153. doi: 10.3389/

fnsys.2010.00153

This magisterial article is concerned with the effects of octopamine modulation on the quantity of activity that occurs in a variety of well-studied model nervous systems. It particularly notes the effects of such neuromodulation on the magnitude of the responses found in the visual system of Limulus, the horseshoe crab.

We here wish to note that such neuromodulation also affects the latencies and timing of neural responses in this same crab's visual system. Specifically, we (Lim et al., 2008) found that octopamine delays and prolongs the intracellular receptor potentials (RPs) recorded from excised Limulus photoreceptors while substance $\mathrm{P}$ accelerates such RPs. Further electroretinographic studies in intact crabs (Bolbecker et al., 2009) confirmed that such alterations in RP latencies are fully natural effects of these neuromodulators because they can also be produced by physiologic efference that varies with time-of-day.

Finally, we note that such effects have properties that make efferent neuromodulation a candidate for the mediation of human visual attention (cf. Wasserman et al., 2011). If that candidacy is confirmed, new methods of diagnosing and treating attention disorders will become feasible.

\section{REFERENCES}

Bolbecker, A. R., Lim, C. C. M., Li., J., Swan, A., Lewis, A, Fleets, J., and Wasserman, G. S. (2009). Visual efference neuromodulates retinal timing: in vivo roles of octopamine, substance $\mathrm{P}$, circadian phase, and efferent activation in Limulus. J. Neurophysiol. 102, 1132-1138. doi: 10.1152/jn.91167.2008

Lim, C. C. M., Bolbecker, A. R., Li, J., and Wasserman, G. S. (2008). Visual efference in Limulus: in vitro temperature-dependent neuromodulation of photoreceptor potential timing by octopamine and substance P. Vis. Neurosci. 25, 83-94.

Wasserman, G. S., Bolbecker, A. R., Li, J., and LimKessler, C. C. M. (2011). A top-down and bottom-up component of visual attention. Cogn. Comput. doi: 10.1007/s12559-010-9058-z. [Epub ahead of print].

Received: 30 December 2010; accepted: 26 January 2011; published online: 08 February 2011.

Citation: Wasserman GS, Bolbecker AR, Li J and LimKessler CCM (2011) Octopamine affects the timing of retinal responses in Limulus as well as their amplitudes. Front. Integr. Neurosci. 5:1. doi: 10.3389/fnint.2011.00001 Copyright (C) 2011 Wasserman, Bolbecker, Li and LimKessler. This is an open-access article subject to an exclusive license agreement between the authors and Frontiers Media SA, which permits unrestricted use, distribution, and reproduction in any medium, provided the original authors and source are credited. 